\title{
Segmental duration in nuclear and post-nuclear syllables in Russian
}

Tatiana Kachkovskaia, Mayya Nurislamova

Department of Phonetics, Saint Petersburg State University, Russia

https://doi.org/10.36505/ExLing-2018/09/0014/000347

\begin{abstract}
In this paper we compared durational patterns of two types of nuclei, HL* (used to signal contrast, in addresses, exclamations etc.) and $\mathrm{H}^{*} \mathrm{~L}$ (used in yes/no questions and non-final phrases), for which the role of post-nucleus is different. In a laboratory experiment with the target word "Natasha" placed in different contexts we found that the two types of nuclei differ in the duration of both stressed and post-stressed syllable. The stressed syllable is longer in $\mathrm{HL}^{*}$, while the post-stressed vowel is significantly longer for $\mathrm{H}^{*} \mathrm{~L}$, where post-nucleus plays a greater role. However, this only holds true when the target word occurs phrase-finally. If the nucleus occurs phrase-medially, the temporal difference between $\mathrm{HL}^{*}$ and $\mathrm{H}^{*} \mathrm{~L}$ is much weaker.
\end{abstract}

Key words: prosody, segmental duration, Russian, general question, contrastive stress

\section{Introduction}

In Russian intonation system, there are two common types of nuclei which differ in the role of post-nuclear part. They are:

A rise-fall with an early peak, used in addresses, demands or phrases with contrast, logical stress etc. (in terms of ToRI, HL* (Odé 2008)). Most of the pitch curve is within the nucleus, and the post-nuclear part does not play a significant role.

A rise-fall with a late peak, used in yes/no questions or non-final phrases (in terms of ToRI, $\mathrm{H}^{*} \mathrm{~L}$ ). Within the system, this type of nuclei differs from a "rise + level high" $\left(\mathrm{H}^{*} \mathrm{H}\right)$, which is used in exclamations, often with admiring or dreaming connotation. The key difference between $\mathrm{H}^{*} \mathrm{~L}$ and $\mathrm{H}^{*} \mathrm{H}$ is concentrated within the post-nucleus. Hence the large role of post-nucleus for $\mathrm{H}^{*} \mathrm{~L}$ (see Figure 1).

We hypothesized that if the post-nucleus plays different roles in these two contours, they might differ in durational patterns as well - in particular, we will look for differences in the stressed and post-stressed syllables.

We have to bear in mind that when the nucleus occurs phrase-finally, another factor comes into play - pre-boundary lengthening. The experiment should be designed so as to take this factor into account.

ExLing 2018: Proceedings of 9th Tutorial and Research Workshop on Experimental Linguistics, 28-30 August, Paris, Frannce 


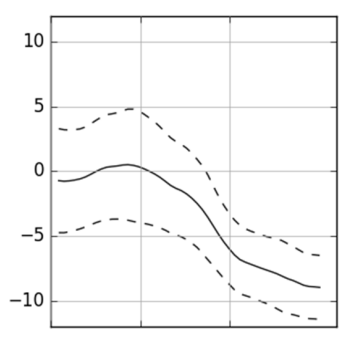

$\mathrm{HL}^{*}$

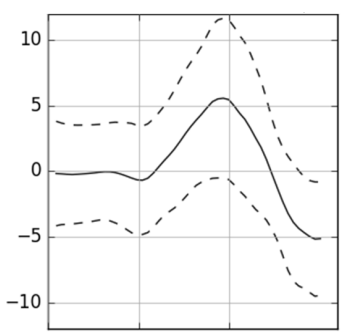

$\mathrm{H}^{*} \mathrm{~L}$

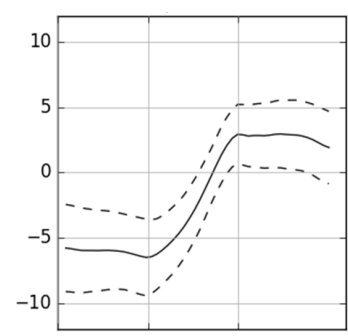

$\mathrm{H}^{*} \mathrm{H}$

Figure 1. Average pitch curves of the 3-syllable word with penultimate stress in semitones based on CORPRES (Skrelin et al. 2010). Dashed lines show standard deviation. Vertical grey lines mark syllable boundaries.

\section{Experimental method and results}

In order to test this hypothesis, we performed a production experiment, where speakers were asked to read a set of utterances containing the target word "Natasha" (/na'ta a/, a female name with penultimate stress) in five different contexts. In order to elicit the intended melodic contours, the speakers were instructed to put emphasis on the words given in bold.

Neutral context. “Сегодня Наташа на рисовании.” (Today Natasha [is] at [the] drawing class.)

Contrastive stress (reassuring) in phrase-final position. “Аа нет же, приходила Наташа!” (Not at all, came Natasha!)

Contrastive stress (reassuring) in phrase-medial position. "Вчера Наташа приходика, а не Марина.” (Yesterday Natasha came, not Marina.)

Yes/no question (with a hint of surprise) in phrase-final position. "Что? Приходила Наташа?” (What? Came Natasha?)

Yes/no question (with a hint of surprise) in phrase-medial position. "Прав_а? Сегодня Наташа приходила?” (Really? Today Natasha came?)

The material was recorded from six speakers aged 22-50, 3 males and 3 females. All the speakers pronounced the utterances as expected: HL* for contexts 2 and 3, $\mathrm{H}^{*} \mathrm{~L}$ for contexts 4 and 5, no nuclear stress for context 1 . The target words were manually segmented into sounds. The utterance-final vowels were judged to end with the end of formant structure.

The duration data for all 6 speakers are shown if Figure 2. 


\section{Phrase-final contexts}

The stressed syllable, /ta/, was longer in context 2 (contrast) compared with context 4 (yes/no question) for all speakers. The difference ranged between 29 to $46 \mathrm{~ms}$, and most of it was due to the vowel duration.
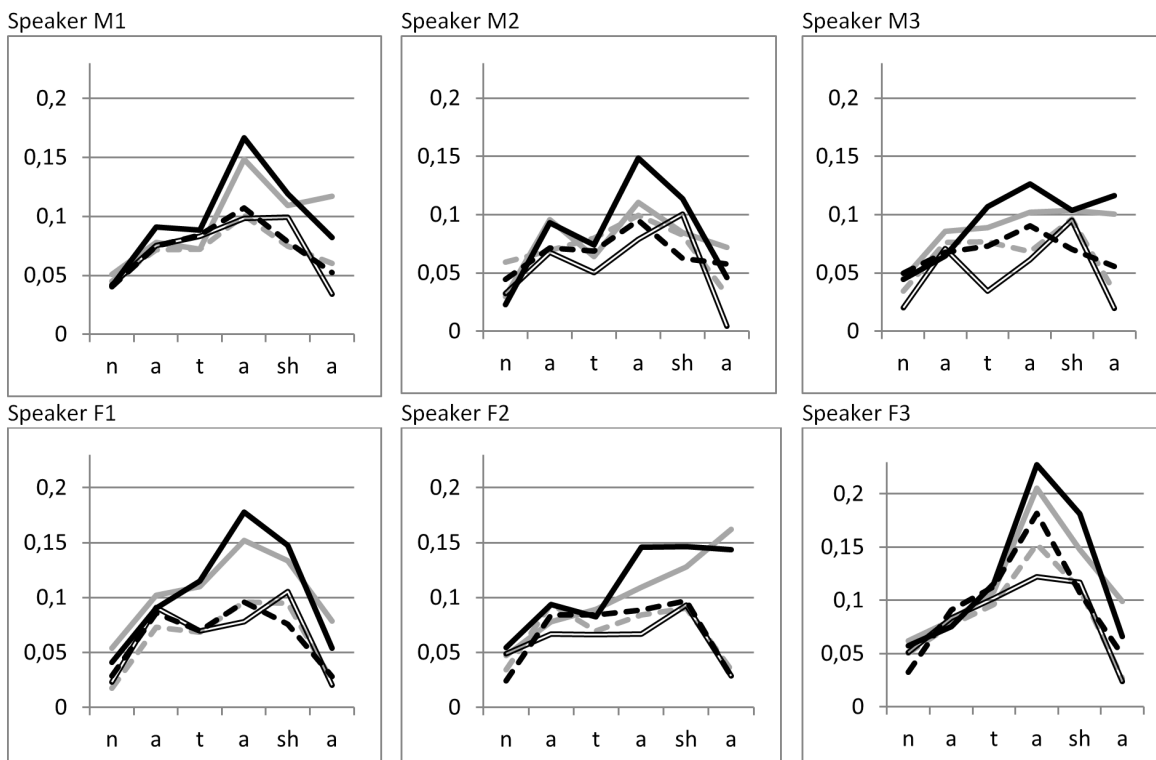

Speaker F2

Speaker F3
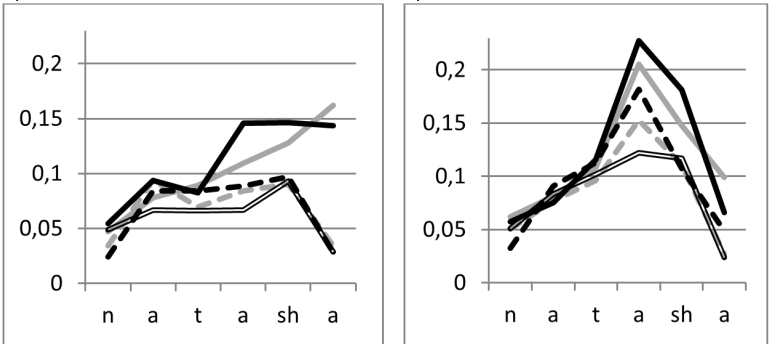

$\mathrm{Y} / \mathrm{N}$ question Final - - $\mathrm{Y} / \mathrm{N}$ question Medial —C Conrast Final - - Contrast Medial $\longrightarrow$ Neutral

Figure 2. Duration (in $\mathrm{ms}$ ) of the segments within the target word "Natasha" for 6 speakers and 5 different contexts (see legend)

The post-stressed syllable, $/ \mathrm{Ja} /$, for context 2 was either of the same duration or shorter than for context 4 for all speakers but M3. If shorter, the difference ranged between 10 and $25 \mathrm{~ms}$. Interestingly, the vowel of the post-stressed syllable was significantly shorter for context 2 for these 5 speakers. The difference ranged between 18 and $35 \mathrm{~ms}$. The consonant of the syllable $/ \mathrm{da} /$, on the other hand, was in most cases longer for context 2 than for context 4 , and thus seems to be compensating for vowel lengthening. However, in our example the consonant is unvoiced, so this might not be the case with sonorants or voiced obstruents.

Thus, for context 4 (yes/no question), where post-nucleus plays a larger role, post-stressed vowel has higher duration. This might be explained by the fact that speakers need more time to show that pitch is going down; otherwise this tune might be confused with another one - 
"rise + level high" - which in its turn would led to misunderstanding, as the latter contour never marks a question.

The exception, speaker M3, might use a different strategy for temporal marking of these two types of nuclei. More research is needed to find out how frequent this strategy is among Russian speakers.

\section{Phrase-medial contexts}

The duration data for phrase-medial show much more variation across speakers. The stressed syllable, /ta/, was longer in context 3 (contrast) compared with context 5 (yes/no question) for 4 speakers; the difference ranged between 18 and 46 ms. Speaker M2 showed an opposite effect, and speaker F1 - almost no difference ( $2 \mathrm{~ms})$.

For the post-stressed syllable, $/ \mathrm{Ja} /$, the difference between contexts 3 and 5 was in most cases rather small ( $7 \mathrm{~ms}$ and less; 4 speakers). For speaker F1 the syllable $/ \mathrm{Ja} /$ is $16 \mathrm{~ms}$ longer in context 5 , while for speaker F3 it is $19 \mathrm{~ms}$ shorter. As for the final /a/, there is no evidence that it is longer in context 5 than in context 3.

\section{Conclusion}

Our data have shown that the two types of nuclei differ in temporal organization, but the latter is highly dependent on whether the nucleus is phrase-final or not. In terms of segmental durations, phrase-final words under nuclear stress are pronounced more carefully, and therefore the melodic difference is supported by difference in duration, while in phrase-medial context the types of nuclei might differ only in terms of melody.

\section{Acknowledgements}

The research is supported by the government of Russia (President's Grant \# MK2194.2017.6).

\section{References}

Odé, C. 2008. Transcription of Russian Intonation, ToRI, An Interactive Research Tool and Learning Module on the Internet. In Dutch Contributions to the Fourteenth International Congress of Slavists, Ohrid: Linguistics (SSGL 34), 431-449. Amsterdam-New York: Rodopi.

Skrelin, P., Volskaya, N., Kocharov, D., Evgrafova, K., Glotova, O., Evdokimova, V. 2010. CORPRES - Corpus of Russian Professionally Read Speech. In Sojka, P., Horak, A., Kopeček, I., Pala, K. (Eds.) Text, Speech and Dialogue. TSD 2010. LNCS, vol. 6231, 392-399. Berlin, Heidelberg: Springer. 